\title{
Air flow influences on local climate: observed and simulated mean relationships for the United Kingdom
}

\author{
Timothy J. Osborn ${ }^{1, *}$, Declan C onway ${ }^{1}$, Mike Hulme ${ }^{1}$, J onathan M. Gregory ${ }^{2}$, \\ Philip D. J ones ${ }^{1}$
}

${ }^{1}$ C limatic Research Unit, School of Environmental Sciences, University of East Anglia, Norwich N R4 7TJ, United Kingdom

${ }^{2} \mathrm{H}$ adley Centre for Climate Prediction and Research, M eteorological Office, London Road, Bracknell RG 12 2SZ,

United Kingdom

\begin{abstract}
Synoptic-scale air flow variability over the United Kingdom is measured on a daily time scale by following previous work to define 3 indices: geostrophic flow strength, vorticity and direction. Comparing the observed distribution of air flow index values with those determined from a simulation with the Hadley Centre's global climate model (HadCM2) identifies some minor systematic biases in the model's synoptic circulation but demonstrates that the major features are well simulated. The relationship between temperature and precipitation from parts of the United Kingdom and these air flow indices (either singly or in pairs) is found to be very similar in both the observations and model output; indeed the simulated and observed precipitation relationships are found to be almost interchangeable in a quantitative sense. These encouraging results imply that some reliability can be assumed for single grid-box and regional output from this climate model; this applies only to those grid boxes evaluated here (which do not have high or complex orography), only to the portion of variability that is controlled by synoptic air flow variations, and only to those surface variables considered here (temperature and precipitation).
\end{abstract}

KEY WORDS: UK Climate · Synoptic circulation · Climate model evaluation · HadCM 2

\section{INTRODUCTION}

Local weather and its statistics (i.e. local climate) are controlled by a combination of large-scale forcing, regional- and synoptic-scale atmospheric circulation (and moisture/temperature characteristics) and local or site characteristics. Interactions occur between these scales. With the exception of the seasonal cycle, variability on time scales from about $1 \mathrm{~d}$ to about $5 \mathrm{yr}$ cannot be explained without consideration of variations in the synoptic climate. The reliability of the local climate (at the grid-box scale, for example) simulated by global climate models (GCMs) will depend to a considerable extent, therefore, on how well such models capture the relationship between synoptic circulation and local climate. These relationships are currently the subject of

*E-mail: t.osborn@uea.ac.uk much interest because of their use in the statistical downscaling (see, e.g., Enke \& Spekat 1997, Wilby et al. 1998, and references therein) of information from the synoptic circulation to generate small-scale weather (e.g. station or catchment precipitation and/or temperature).

In the present paper, however, our interest is in evaluating the reliability of GCMs (in particular, the HadCM 2 GCM of the Hadley Centre, although the methodology could equally be applied to other GCMs). This simplifies the approach somewhat, because we do not necessarily need to identify the method that captures the circulation-climate relationship fully; provided that we have a method that captures most of this relationship, all that is required is that we apply the same method to both observations and model output (i.e. a like-with-like comparison). The method we use is that of Conway et al. (1996), computing values of 3 air flow indices for each day and then averaging the 

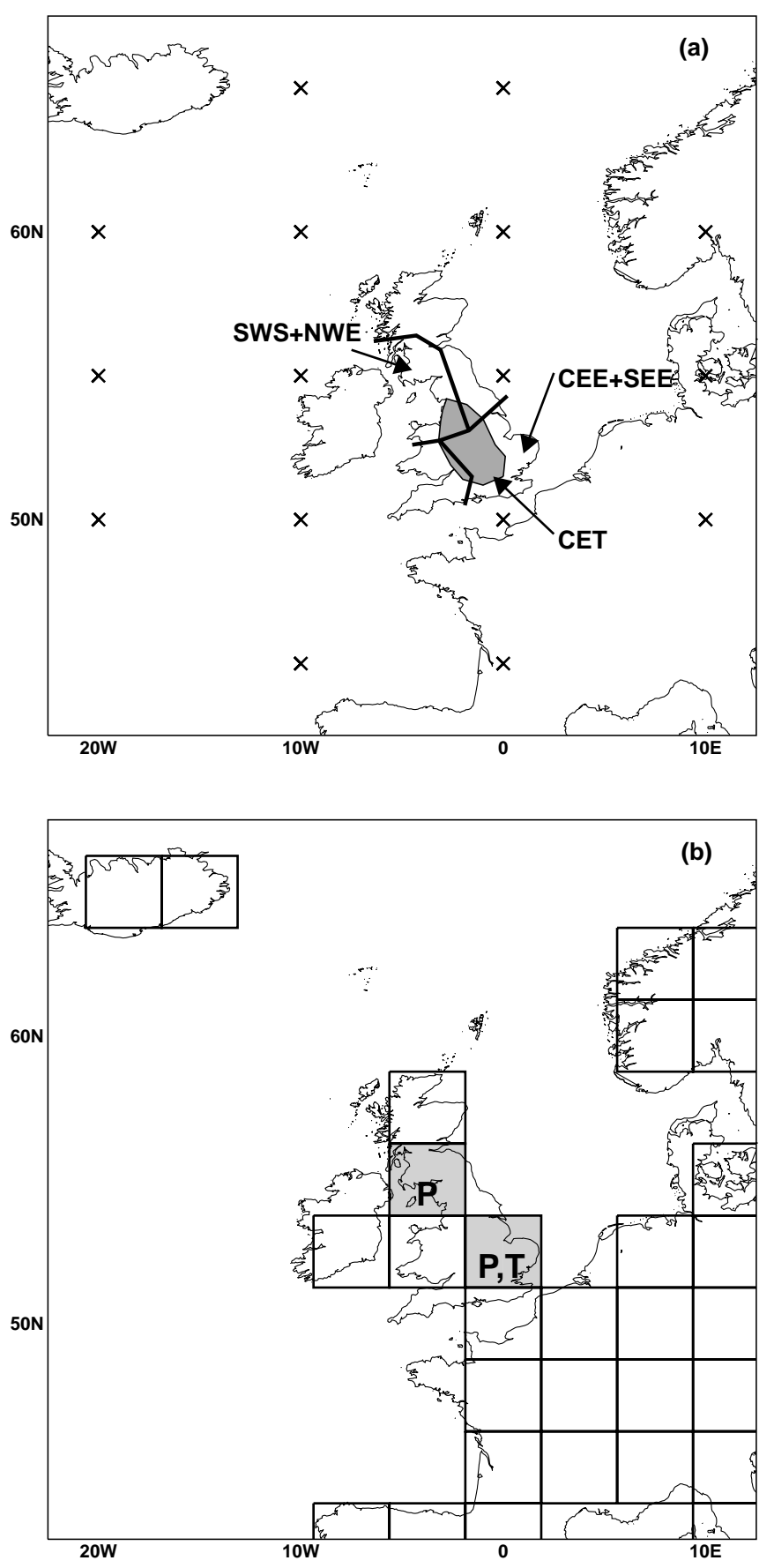

Fig. 1. (a) Location of sea level pressure points $(x)$ used to compute air flow indices, location of the region (shaded) for which the observed Central England Temperature (CET) is representative, and locations of the observed regional precipitation timeseries (delineated by thick lines; land only). SWS+NWE and CEE+SEE are averages of the southwest Scotland and northwest England, and central/eastern England and southeast England, regional precipitation series, respectively. (b) Location of HadCM 2 land grid boxes (lines), the 2 boxes (shaded) from which simulated daily precipitation $(\mathrm{P})$ is taken, and the box from which simulated daily mean temperature $(T)$ is taken temperature and precipitation characteristics of all days that fall into particular air flow index ranges. Other downscaling approaches (Wilby et al. 1998) could be used for GCM validation, although some lack the physical interpretability that the method used here provides.

The application of downscaling techniques to model evaluation has previously been performed at the monthly and seasonal time scales (Noguer 1994, Busuioc et al. 1999), but the focus here is the daily time scale and the single grid-box spatial scale (see also Wilby \& Wigley 1999). This kind of study does not directly help to explain model performance, but it does identify regimes that exhibit systematic errors in the performance of model physics, and which therefore should be made the subject of model improvement. It also provides a more stringent test of the model than a simple evaluation of mean climate, since it tests the model under a wide range of conditions. Osborn \& Hulme (1998) showed that the atmospheric component of HadCM 2 performs well in comparison with other models in terms of its simulation of daily precipitation statistics over Europe.

A general recommendation, particularly from the modelling community, is that output from single model grid boxes should not be used in climate analysis because it is considered to be less reliable than the simulation of larger-scale features. Nevertheless, grid-box output is commonly used, which is why this paper sets out and applies a methodology for evaluating variations in model output at these small spatial scales. Other studies (e.g. Mearns et al. 1990, Palutikof et al. 1997) have highlighted some of the problems with using single grid-box data from climate models.

\section{MODEL AND OBSERVED DATASETS}

Our observed daily data for the United Kingdom (UK) consisted of 3 variables: daily mean temperature, daily total precipitation and daily mean sea level pressure (SLP). The same 3 daily variables were taken from a control simulation of HadCM2 (J ohns et al. 1997), forced by constant radiative forcing applicable to present-day levels of greenhouse gases (although with no anthropogenic sulphate aerosol forcing). From this control integration, $124 \mathrm{yr}$ of complete daily data were available.

The observed temperatures are from the 1881 to 1993 period of the Central England Temperature (CET) record of Parker et al. (1992), representative of the shaded area in Fig. 1a. These were compared with the simulated temperatures from the $\mathrm{HadCM} 2$ grid box covering central and eastern England (Fig. Ib). The long-term mean seasonal cycles (Fig. 2) were com- 
puted on a daily basis; the cold bias in the spring and summer of the simulation is clear (see also Table 1). Each seasonal cycle was smoothed with a 21 d running mean (Fig. 2), and then subtracted from its daily temperature timeseries. By subtracting the observed seasonal cycle from the observed data and the simulated cycle from the simulated data, we removed any bias in the mean simulation so that we could assess the influence of air flow on departures of temperature (anomalies) from the norm.

It is important, particularly for daily precipitation (Osborn \& Hulme 1997), that area-mean rather than single-site observations are used for comparison with the gridbox precipitation (an area average) simulated by climate models. Therefore, the 2 grid-box simulated precipitation timeseries (Fig. 1b) were evaluated by comparison with regional observed precipitation timeseries (Fig. 1a). The focus was on the central and eastern England region, where the observed timeseries is an average of the SEE and CEE timeseries of Gregory et al. (1991, and references therein), each being a combination of 7 station timeseries covering the period 1931 to 1983 . Some results from the comparison between the more northern model grid box and the more northern region (an average of the NWE and SS regions of Gregory et al. 1991) are also presented, since orography is more important there (particularly for the observations, but the model elevation is also higher, being $165 \mathrm{~m}$ compared to $73 \mathrm{~m}$ for the central/eastern England grid box).

No seasonal cycles were removed from the precipitation timeseries (see Table 2 for a comparison of observed and simulated seasonal means). Compared to observations over central and eastern England, HadCM 2 is wetter and has too many wet days (except in autumn), simulates lower wet day amounts in autumn, and fails to capture the summer maximum in intense events. Over the more northern region, HadCM 2 simulates the mean precipitation well in spring and summer, but is drier in winter and particularly autumn.

The HadCM 2 daily SLP was regridded from its $2.5^{\circ}$ latitude by $3.75^{\circ}$ longitude grid onto the same $5^{\circ}$ by $10^{\circ}$ grid that the observed SLP is available on (J ones 1987). Then, 16 grid-point values (Fig. 1a) were used to calculate 3 air flow indices: geostrophic flow strength, $F$, with units $\mathrm{hPa}$ per $10^{\circ}$ latitude at $55^{\circ} \mathrm{N}$ (each unit is equivalent to 1.2 knots), geostrophic vorticity, Z, with units $\mathrm{hPa}$ per $10^{\circ}$ latitude at $55^{\circ} \mathrm{N}$ (100 units being equivalent to 0.46 times the Coriolis parameter at $55^{\circ} \mathrm{N}$ ), and geostrophic flow direction, $\mathrm{D}$, with $0^{\circ}$ and $360^{\circ}$ representing flow from the north, $90^{\circ}$ from the east, $180^{\circ}$ from the south, etc. Jenkinson $\&$ Collison (1977) and J ones et al. (1993) describe and evaluate the basis for these calculations. The small artificial downward trend in the HadCM 2 simulated SLP (see Appen$\operatorname{dix}$ A of Osborn et al. 1999) does not affect the results of the present study because all the air flow indices are computed from pressure differences rather than from absolute pressure values.

\section{SIM ULATION OF DAILY AIR FLOW VARIABILITY}

The observed distributions of air flow index values for the UK have been shown before on an annual basis (Conway et al. 1996), but we extend their work by showing the seasonal distributions and comparing them with the distributions simulated by $\mathrm{HadCM} 2$ (Fig. 3). In this, and subsequent figures, each index is divided into 20 bins (defined in the legend of Fig. 3) and all days with an index value that falls within a particular bin (range) are used to identify the frequency of occurrence and the climate characteristics of those days. The shading in Fig. 3 (and Figs. 4 to 7) shows the range into which the simulated results could fall and still be statistically indistinguishable from the observed results with $90 \%$ confidence-i.e. shading is between the 5 and $95 \%$ cutoff values. A ppendix 1 gives details of their estimation. For Fig. 3, each simulated distribu- 


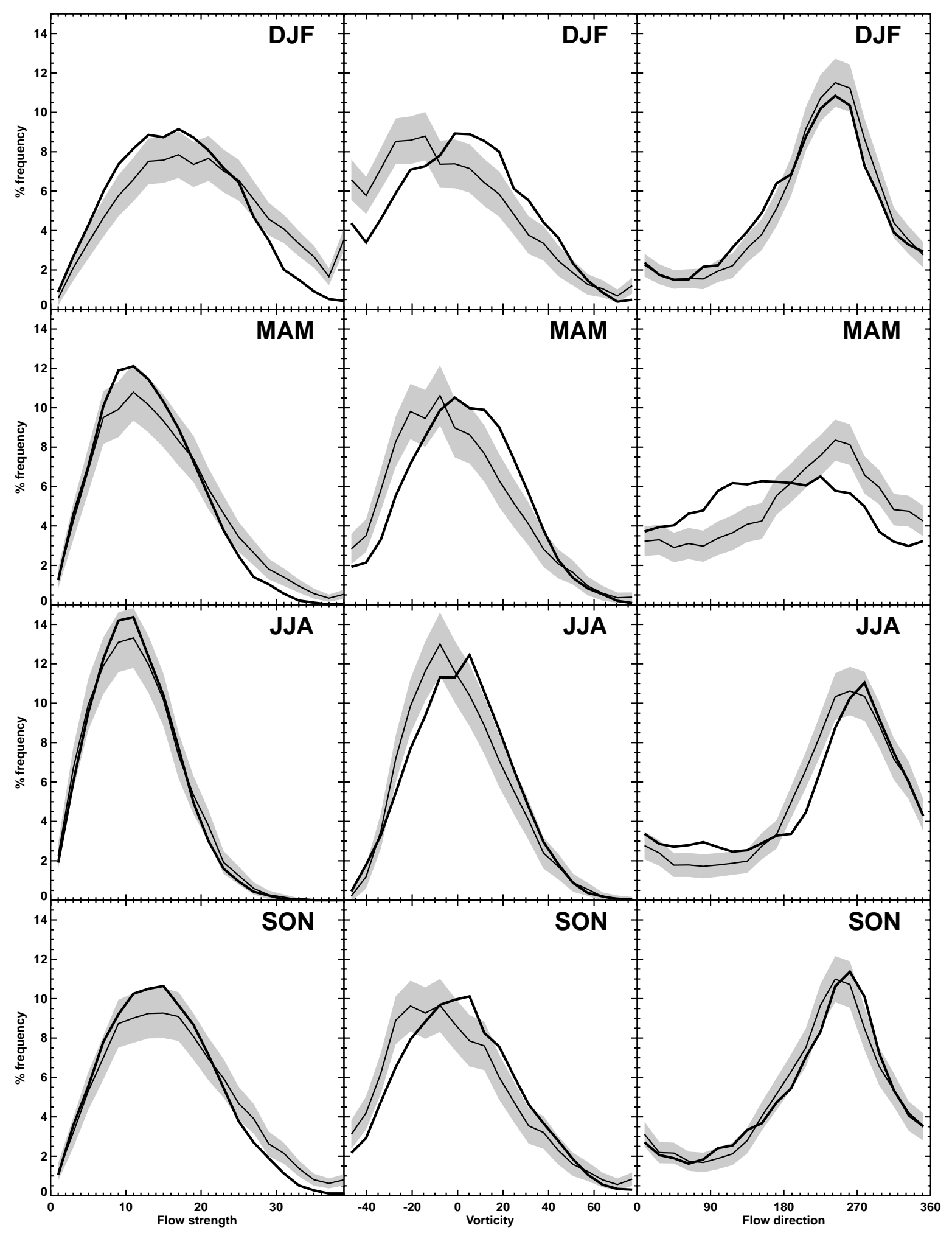

Fig. 3. Frequency with which daily air flow indices fall into particular bins on a seasonal basis $(D) F=$ winter, $M A M=s p r i n g$, JJ A = summer, SON = autumn). Each index is divided into 20 bins, with open-ended extreme bins. Flow strength: bin size =2; vorticity: bin size $=6.5$; flow direction: bin size $=18^{\circ}$. Thick line: HadCM2; thin line: observations (shading: $90 \%$ interval for comparing the simulated values with those observed - see Appendix 1) 
tion can also be compared with the observed distribution via a $\chi^{2}$ test; results indicate that all distributions are significantly different from those observed, with the exception of flow strength in summer. This is consistent with the confidence intervals shown in Fig. 3, since summer flow strength is the only index for which all simulated values lie within the confidence intervals.

The seasonal shift in the flow strength distribution (skewed towards weaker flow in summer and stronger flow in winter) is well captured by HadCM2. The model simulation, however, significantly overestimates the frequency of moderate flows and underestimates the high-flow-strength end of the distribution. The seasonally changing shape of the vorticity distribution is also well captured, but the simulation is not skewed towards anticyclonic (negative vorticity) conditions as much as is observed. The predominance of observed flow between southwesterly and westerly directions in winter, summer and autumn is clear from Fig. 3. The model captures this pattern too, particularly so in winter and autumn. The weakest distribution is of flow direction in spring, and this is simulated least well by HadCM 2.

Hulme et al. (1993) evaluated the simulation of weather types (derived objectively from the air flow indices used here) by an earlier climate model (UKHI) of the UK Meterological Office. The UKHI model underestimated anticyclonic types and overestimated cyclonic types in all seasons except autumn. As noted above, a similar error in the vorticity distribution is present in HadCM 2, though to a much smaller degree compared with the biases in UKHI. The UKHI biases in directional types noted by Hulme et al. (1993) have mainly been removed, except for the overestimated frequency of spring easterlies, at the expense of westerlies and northwesterlies. This spring directional bias is at least as large in $\mathrm{HadCM} 2$ as it was in UKHI, and still occurs even if all weak flow days (whose flow direction is less well defined) are excluded. We note that UKHI already showed a realistic distribution of winter wind direction (Gregory \& Mitchell 1995) and this has been maintained in HadCM2 (in terms of geostrophic flow direction).

\section{INFLUENCE OF AIR FLOW ON TEM PERATURE}

Gregory \& Mitchell (1995) evaluated the dependence of simulated temperature over southern England on wind direction for the winter simulation of the UKHI model. Here, we repeat this analysis for the HadCM 2 model, and extend it to all seasons and to the 3 air flow indices (Fig. 4 shows the mean temperature anomalies of all days that fall into each air flow index bin). Flow strength and vorticity are strong controllers of temperature during winter, with the still, clear air related to weak flow and/or strong anticyclonicity leading to radiative cooling and cold daily mean temperatures. The winter vorticity relationship is too strongly simulated, a bias that worsens during spring. With that exception, the model simulation is very good, even capturing the more subtle summer relationships.

The central England temperature anomalies, however, are most strongly dependent upon flow direction, with a seasonal shift between warm (cold) winter westerlies (easterlies) and cold (warm) summer westerlies (easterlies). The HadCM 2 simulation captures the shape and seasonality well (Fig. 4). The range of mean anomalies is, however, slightly too strong in all seasons, but a large improvement over UKHI, where the winter range was double that observed (Gregory \& $M$ itchell 1995). In that model, the enhanced range was caused by easterlies that were too cold, which then drove down the simulated mean winter temperature over England to more than $6^{\circ} \mathrm{C}$ colder than observed.

While the mean errors are much smaller in HadCM 2 (Table 1) than in UKHI (Gregory \& M itchell 1995), it is still of interest to use our results to diagnose the source of the remaining model biases. The curves in Fig. 4 are all computed from the mean of the temperature anomalies of days with particular air flow index values, with the mean seasonal cycles of temperature having first been removed. Had the means not been subtracted before the analysis, or if the observed means had been subtracted from both observed and simulated temperatures, the effect would have been to move the simulated curves in Fig. 4 down by about $1.2^{\circ} \mathrm{C}$ in spring and summer, down by $0.3^{\circ} \mathrm{C}$ in autumn and up by $0.3^{\circ} \mathrm{C}$ in winter relative to the observational results (see Table 1). The largest apparent model errors are in

Table 1. Seasonal mean temperatures $\left({ }^{\circ} \mathrm{C}\right)$ observed over central England, and simulated over central and eastern England. Observed values are from the 1881 to 1993 period; simulated values come from the HadCM 2 control integration. The actual model error is given, together with the implied errors due to biases (see text for bias calculation), in the simulated univariate and bivariate distributions of air flow index values ( $F=$ flow strength, $Z=$ vorticity, $D=$ flow direction)

\begin{tabular}{|lcccc|}
\hline & DJF & MAM & JJA & SON \\
\hline Observed & 4.06 & 8.28 & 15.28 & 9.90 \\
HadCM2 & 4.37 & 7.12 & 14.06 & 9.63 \\
'Error' & & & & \\
(M odel-Obs) & +0.31 & -1.16 & -1.22 & -0.27 \\
F bias & -0.35 & -0.09 & -0.05 & -0.06 \\
Z bias & +0.38 & +0.30 & -0.06 & +0.11 \\
D bias & -0.14 & -0.06 & -0.08 & -0.03 \\
F, Z bias & +0.03 & +0.19 & -0.06 & +0.03 \\
F, D bias & -0.36 & -0.15 & -0.09 & -0.08 \\
Z, D bias & +0.31 & +0.17 & -0.13 & +0.08 \\
\hline
\end{tabular}




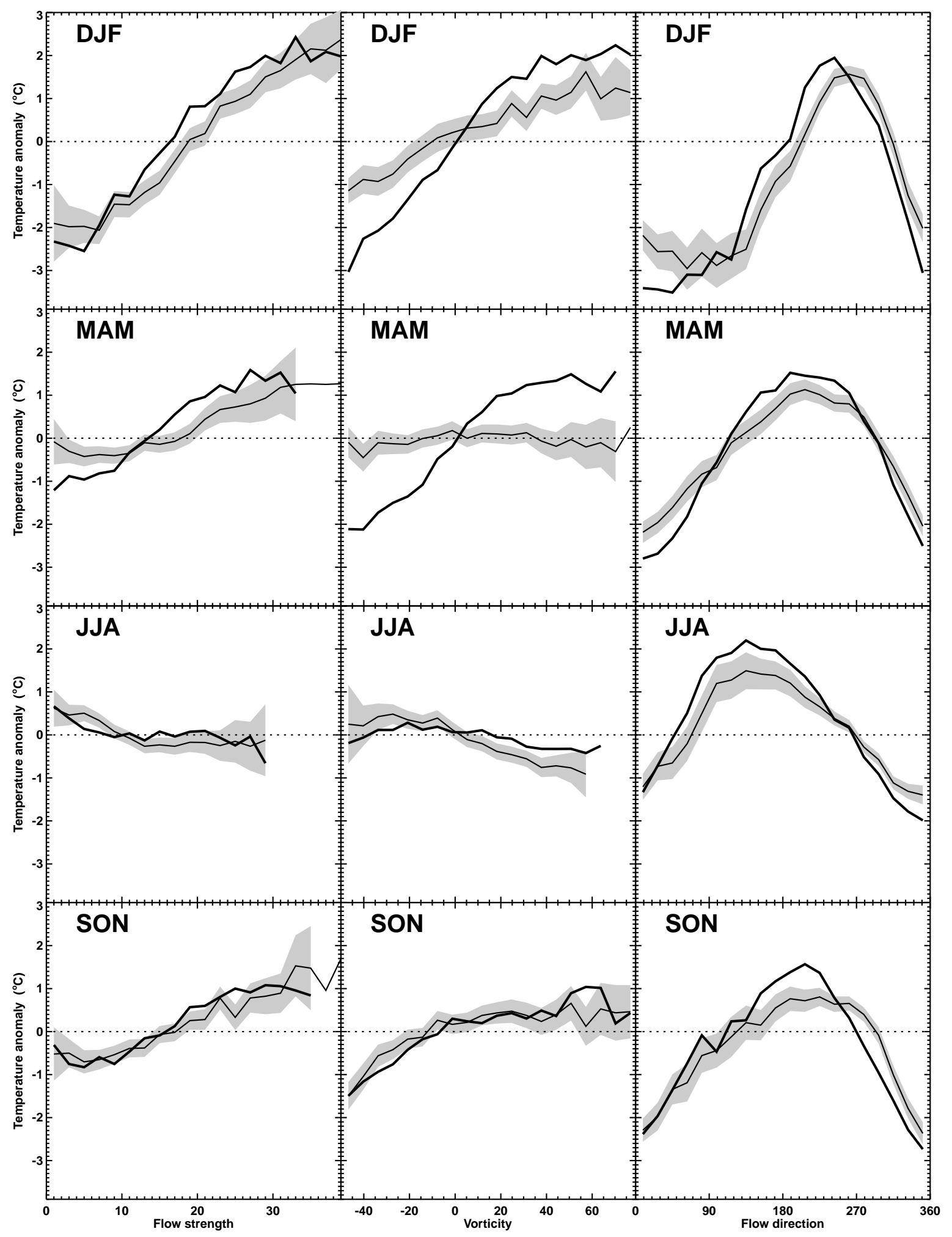

Fig. 4. Mean temperature anomaly of days whose air flow indices fall into particular bins, on a seasonal basis and for the 3 indices. Bin sizes, lines and shading are defined in Fig. 3. Only values computed from a sample of at least $20 \mathrm{~d}$ are shown 
spring and summer, when the simulated temperature is too cold (Table 1); shifting the relationships shown in Fig. 4 to include this bias would show that it is spring and summer northerlies that are particularly too cold in HadCM 2.

In addition to errors in the temperature characteristics associated with flow properties (Fig. 4), we have already identified some biases in the frequency with which some flow properties occur (Fig. 3). To assess the impact on mean temperature of the latter biases, we can combine the simulated temperature-flow relationship with the observed frequency of air flow index values to obtain the implied temperature bias (by multiplication of the temperature anomaly associated with each bin by the frequency of occurrence of the bin, followed by summation over all the air flow index bins). The results depend on which season and which air flow variable is used, and are summarised in Table 1. For example, consider vorticity: in all seasons, except summer, positive vorticity is associated with anomalously warm temperatures in HadCM 2; the positive skew of the HadCM 2 vorticity distribution relative to observations (Fig. 3) thus implies temperatures in winter, spring and autumn ( $Z$ bias in Table 1 ) are warmer than would have occurred with the observed vorticity distributions. The vorticity bias might, therefore, partly cause the HadCM 2 warm bias in winter, but cannot explain the mean temperature errors of the other seasons. We say 'might', because the temperature effects implied by the biases in the flow strength distributions (Fig. 3) are of opposite sign to those implied by the vorticity biases (Table 1), except in summer. Whether the different effects can simply be summed depends upon whether the different air flow indices are independent of each other in the determination of temperature. This is considered further in Section 6.

Finally, note that the air flow index with the most biased distribution is the flow direction in spring
(Fig. 3). This large error does not imply a large mean temperature bias (Table 1, D bias), however, due to cancellation of opposite temperature anomalies and because the frequencies of the warmest (southerly) and coldest (northerly) flows are well simulated (see Figs. $3 \& 4)$.

\section{INFLUENCE OF AIR FLOW ON PRECIPITATION}

The temperature analysis was repeated for daily precipitation totals (Fig. 5). The seasonal means were not removed prior to this analysis because the seasonal cycle is fairly weak and interpretation of the results is not hindered. It should be borne in mind that differences in the seasonal means between observations and model (Table 2) will be apparent in the circulation-precipitation results. As expected (from the results of, e.g., Conway et al. 1996), vorticity is the strongest control on precipitation over central and eastern England, in all seasons and in the simulated data too (Fig. 5). The reduction in mean precipitation with increasingly negative vorticity is well captured by $\operatorname{HadCM} 2$; it is at the high-vorticity end that model errors are apparent, with less precipitation than observed on winter and autumn days with high vorticity, and slightly too much in summer.

The weaker dependencies on flow strength and direction are well captured in the model simulation, once mean errors (Table 2) are ignored. The only exception to this is that wettest spring and summer conditions are associated with easterlies in the observed record, but with southerlies in HadCM 2.

The northwest England and southwest Scotland regional observed and grid-box simulated precipitation provides an interesting comparison. Orography is more important here, and the region is also more central within the group of SLP points used to compute the

Table 2. Seasonal mean precipitation $\left(\mathrm{mm} \mathrm{d}^{-1}\right)$, probability of a wet day (at least $1 \mathrm{~mm}$ ), and mean precipitation amount on days with at least 0.1 or $5 \mathrm{~mm}$, as observed and as simulated over central/eastern England (C\&EE) and over northwest England/southwest Scotland (NWE\&SWS). Observed values are from the 1931 to 1983 period; simulated values come from the HadCM 2 control integration

\begin{tabular}{|c|c|c|c|c|c|c|}
\hline Region & Dataset & Statistic & $D J F$ & MAM & JJA & SON \\
\hline \multirow[t]{8}{*}{$C \& E E$} & Observed & Mean & 1.85 & 1.57 & 1.79 & 2.05 \\
\hline & $\mathrm{HadCM} 2$ & Mean & 2.33 & 1.95 & 2.21 & 1.89 \\
\hline & Observed & $P$ (wet) & 0.41 & 0.37 & 0.37 & 0.40 \\
\hline & $\mathrm{HadCM} 2$ & $P$ (wet) & 0.46 & 0.47 & 0.49 & 0.38 \\
\hline & Observed & Mean $(>0.1)$ & 2.65 & 2.58 & 3.03 & 3.11 \\
\hline & $\mathrm{HadCM} 2$ & Mean $(>0.1)$ & 2.68 & 2.44 & 3.05 & 2.54 \\
\hline & Observed & Mean (>5) & 8.23 & 8.17 & 9.10 & 9.21 \\
\hline & $\mathrm{HadCM} 2$ & Mean (>5) & 8.80 & 7.78 & 7.58 & 8.78 \\
\hline \multirow[t]{2}{*}{ NWE\&SWS } & Observed & Mean & 3.59 & 2.50 & 2.81 & 4.11 \\
\hline & $\mathrm{HadCM} 2$ & Mean & 2.98 & 2.39 & 2.90 & 2.82 \\
\hline
\end{tabular}




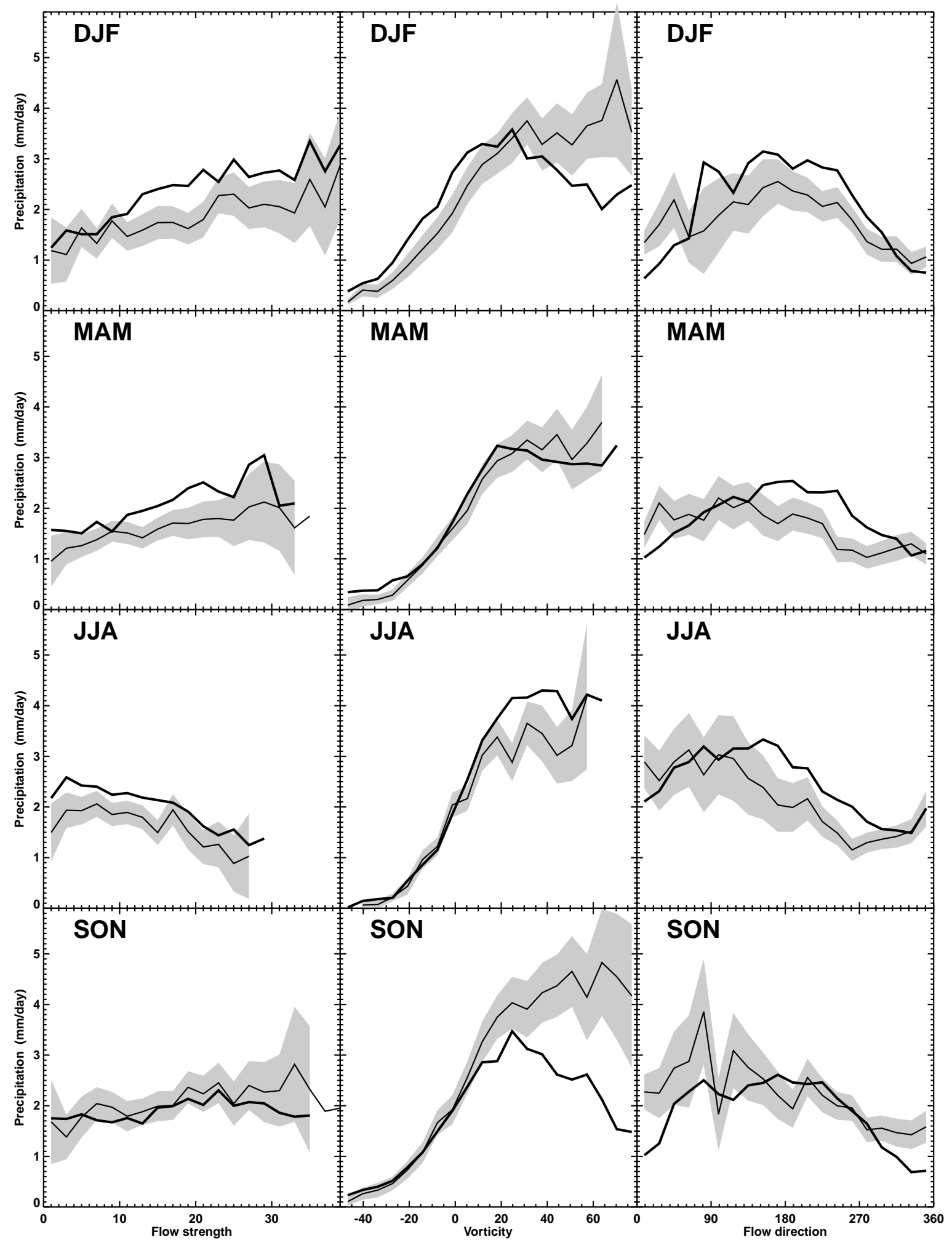

Fig. 5. Central and eastern England mean precipitation of days whose air flow indices fall into particular bins, on a seasonal basis and for the 3 indices. Bin sizes, lines and shading are defined in Fig. 3. Only values computed from a sample of at least $20 \mathrm{~d}$ are shown 
air flow indices (Fig. 1). Vorticity is still the key controlling factor on precipitation for much of the year (Fig. 6), and the model still underestimates the mean precipitation on winter and autumn days with positive vorticity (indeed, the bias is somewhat worse than it was for the central and eastern region of England). For the more northern region, however, both flow strength and flow direction have increased in importance, particularly in winter and autumn (as previously noted by Wigley \& J ones 1987). Wet and windy go together, with the relationship somewhat stronger in the observed data (Fig. 6), even though gauges may underestimate rainfall in windy weather. In the observations, southwesterlies are associated with the greatest precipitation in all seasons, while HadCM 2 has southerlies as being the wettest.

Returning now to the central and eastern region of England, we break the mixed-type precipitation distribution into its constituents: What is the probability of precipitation occurring, how much falls on a wet day, and how do these variables depend upon the synoptic flow conditions? The seasonal mean values are given in Table 2, while the relationships with the air flow indices are given in Fig. 7 (for the probability of at least $1 \mathrm{~mm}$ falling on a particular day) and Fig. 8 (for the mean amounts falling on those days that had at least $0.1 \mathrm{~mm}$ or at least $5 \mathrm{~mm}$ of precipitation).

Comparing Figs. 5 and 7, it is immediately obvious that the probability of a wet day shows a very similar dependence on air flow as the mean precipitation does, and further that the HadCM 2 biases show a very similar structure in both figures. It is the probability of a wet day, therefore, that captures most of the air flow influence on mean precipitation, with the mean wet day amounts showing much less dependence on synoptic air flow (Fig. 8). The mean wet day amount of almost all wet days $(>0.1 \mathrm{~mm}$ ) shows some dependence on air flow, particularly vorticity. Increasing the threshold weakens the relationships, so that when only days with at least $5 \mathrm{~mm}$ of precipitation are considered the mean amount is insensitive to flow strength and vorticity and only slightly sensitive to flow direction (Fig. 8, upper curves in each panel).

Despite the weaker relationships with wet day amount, the HadCM 2 model exhibits a structure that is very similar to that observed-in particular, note the improvement in the dependence of wet day amount on flow direction (Fig. 8) compared to the mean precipitation (Fig. 5) or probability of a wet day (Fig. 7) dependencies. Taking the more extreme days ( $>5 \mathrm{~mm}$ ), the underestimate by $\mathrm{HadCM} 2$ of the high intensity part of the precipitation distribution in summer is clear (Fig. 8, Table 2). The difference between the simulated and observed wet day amounts on these very wet summer days appears to be less for positive vorticity days than for negative vorticity days (Fig. 8), perhaps indicating that intense summer precipitation originating from frontal mechanisms is better simulated than that originating from convective mechanisms. Note that the reliability of the observed spatial sampling in representing area averages is dependent on the spatial scale of precipitation events (Osborn \& Hulme 1997), perhaps artificially contributing to the enhanced amounts under convective conditions (e.g. summer vs winter or summer anticyclonic vs cyclonic conditions). To what extent this artefact might explain differences between observed and simulated wet day amounts (Fig. 8) is unclear, although the results of Osborn \& Hulme (1997) suggest it will be small because 14 stations are used to compute the regional average.

\section{MULTIVARIATE CONSIDERATIONS}

\subsection{Q uantitative comparisons}

The relationships between temperature or precipitation and air flow indicate the dominance of flow direction in controlling temperature (Fig. 4) and vorticity in controlling precipitation (Fig. 5). Nevertheless, secondary variables may provide important additional controls on local climate. Before considering multi-predictor relationships further, a method of quantifying the skill of the different variables at explaining climate variation s is required. This would also enable a quantitative comparison of the observed and simulated relationships to augment the visual comparison already made.

The procedure is as follows: For a particular air flow variable, its value on a particular day in the observed (or simulated) record is used to compute (by interpolation between the binned values) the mean temperature anomaly (Fig. 4) or mean precipitation (Fig. 5) expected for that air flow value. A timeseries of temperature or precipitation driven by synoptic variability (the 'synoptic signal') can then be built up by repeating this for each day of the record. A residual timeseries is formed by subtracting this synoptic signal timeseries from the original observed or simulated record. The difference between the variance of the residual timeseries and the variance of the original record, expressed as a percentage of the latter variance, yields the percent variance explained by the selected air flow variable.

These statistics are given in the left-hand panels of Figs. $9 \& 10$, for temperature and precipitation respectively (precipitation results are from the central and eastern England region). Comparing the dark grey (observed) and light grey (simulated) bars for temperature highlights the importance of flow strength in win- 


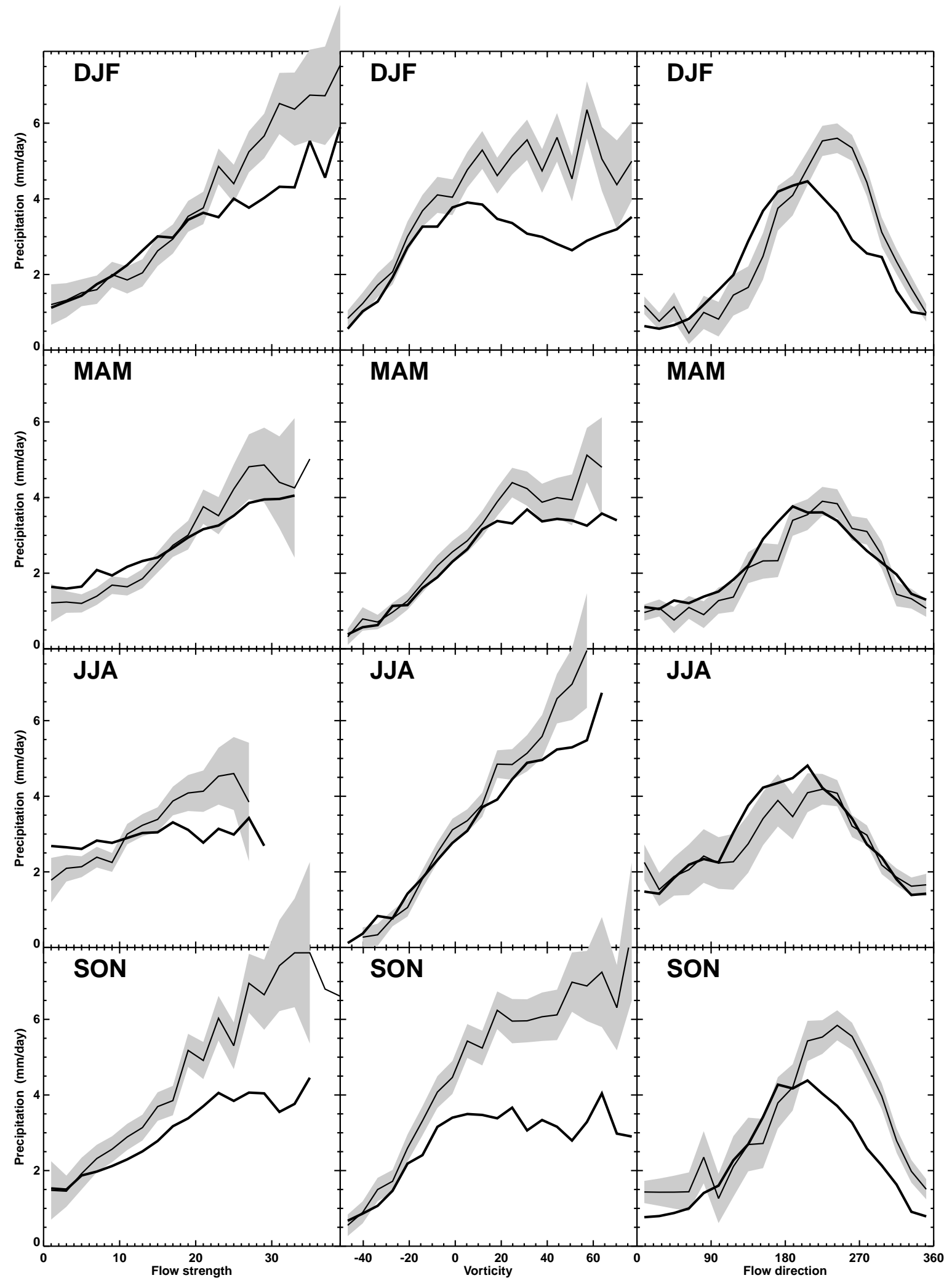

Fig. 6. Northwest England and southwest Scotland mean precipitation of days whose air flow indices fall into particular bins, on a seasonal basis and for the 3 indices. Bin sizes, lines and shading are defined in Fig. 3. Only values computed from a sample of at least $20 \mathrm{~d}$ are shown 


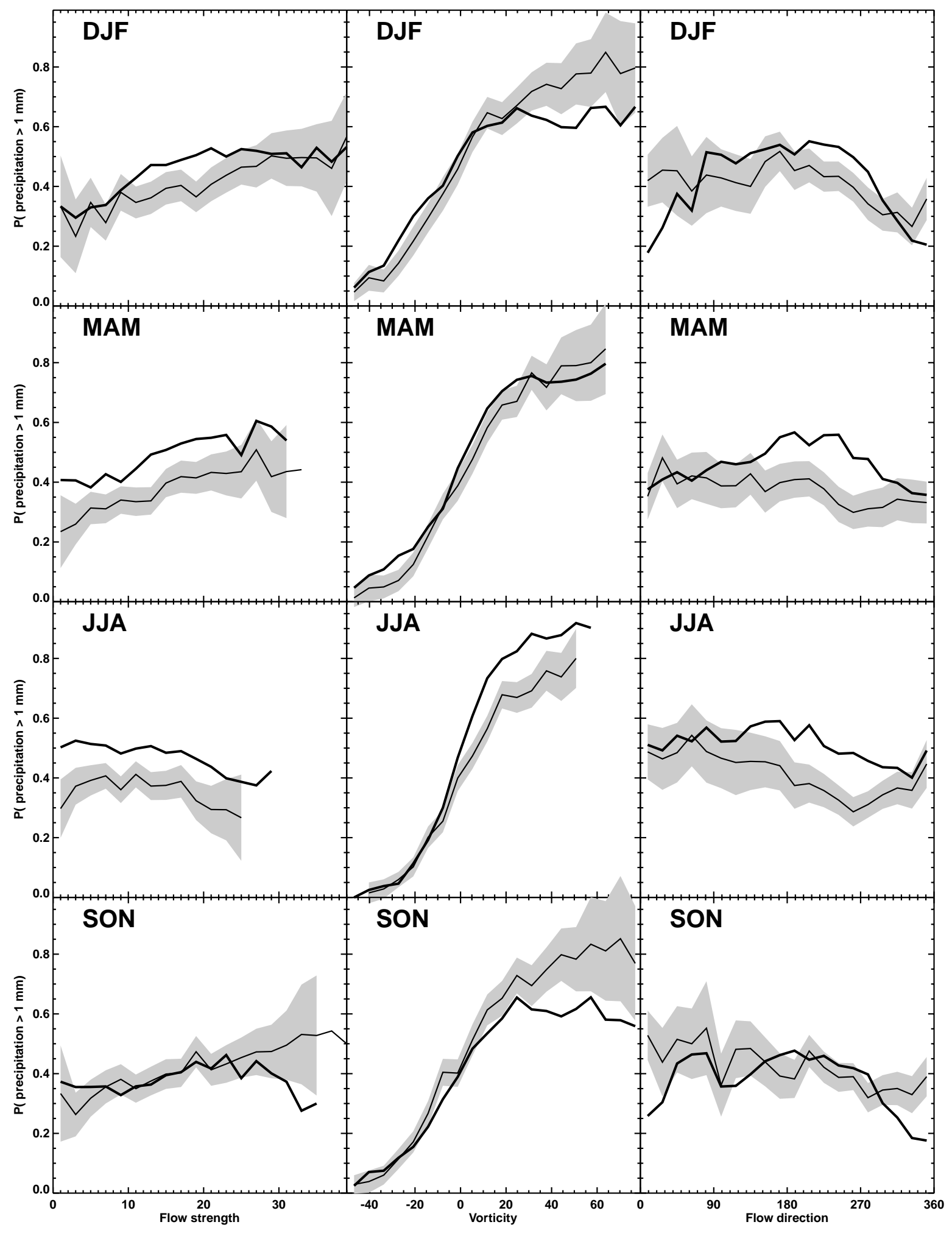

Fig. 7. Probability of a day with $>1 \mathrm{~mm}$ of precipitation in the central and eastern England region for days whose air flow indices fall into particular bins, on a seasonal basis and for the 3 indices. Bin sizes, lines and shading are defined in Fig. 3. Only values computed from a sample of at least $25 \mathrm{~d}$ are shown 


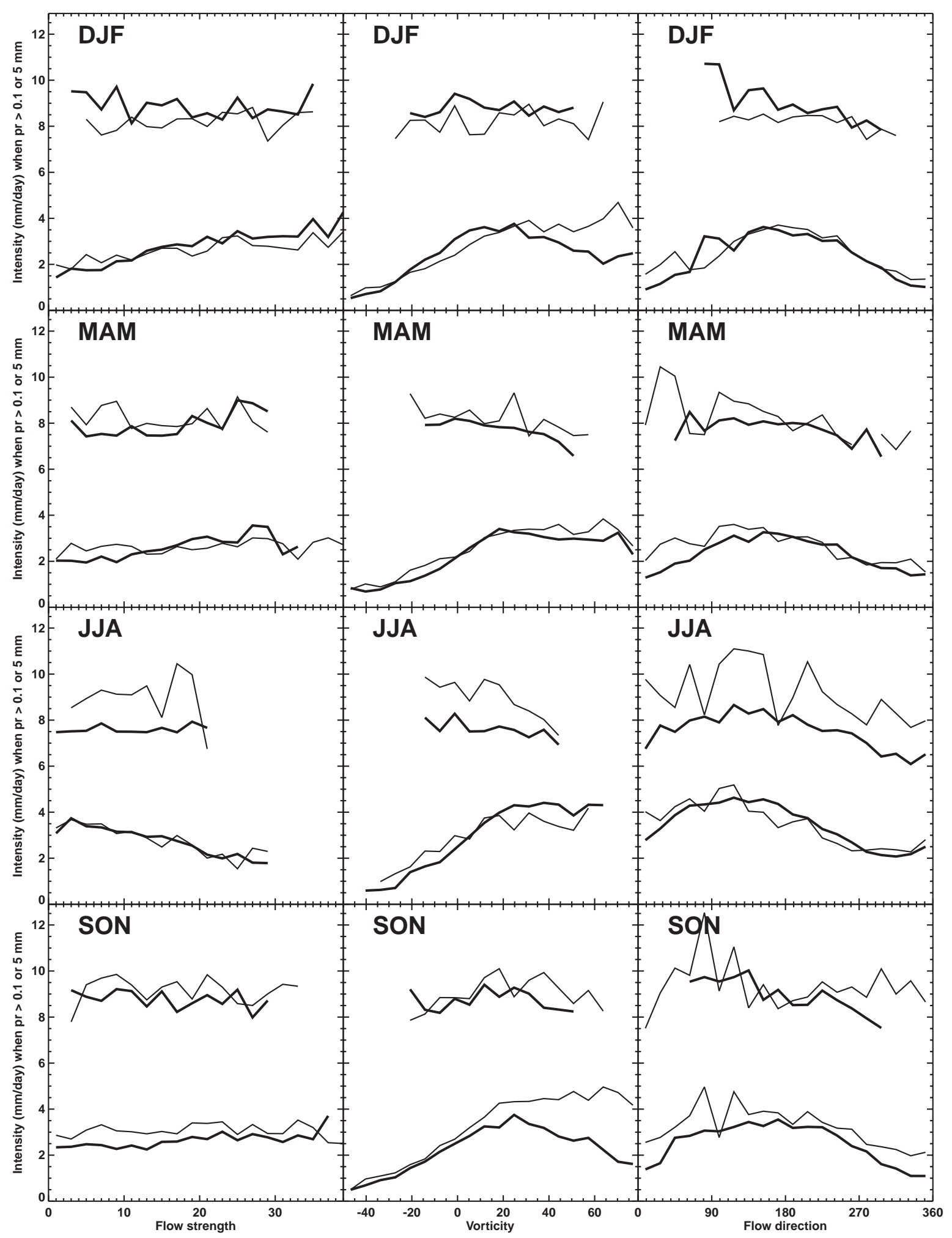

Fig. 8. M ean central and eastern England precipitation $\left(\mathrm{mm} \mathrm{d}^{-1}\right)$ of those days with $>0.1 \mathrm{~mm}$ (lower pairs of lines), or only of those days with $>5 \mathrm{~mm}$ (upper pairs of lines), of precipitation for days whose air flow indices fall into particular bins, on a seasonal basis and for the 3 indices. Bin sizes and lines are defined in Fig. 3. No uncertainty range is given. Only values computed from a sample size of at least $10 \mathrm{~d}$ are shown 

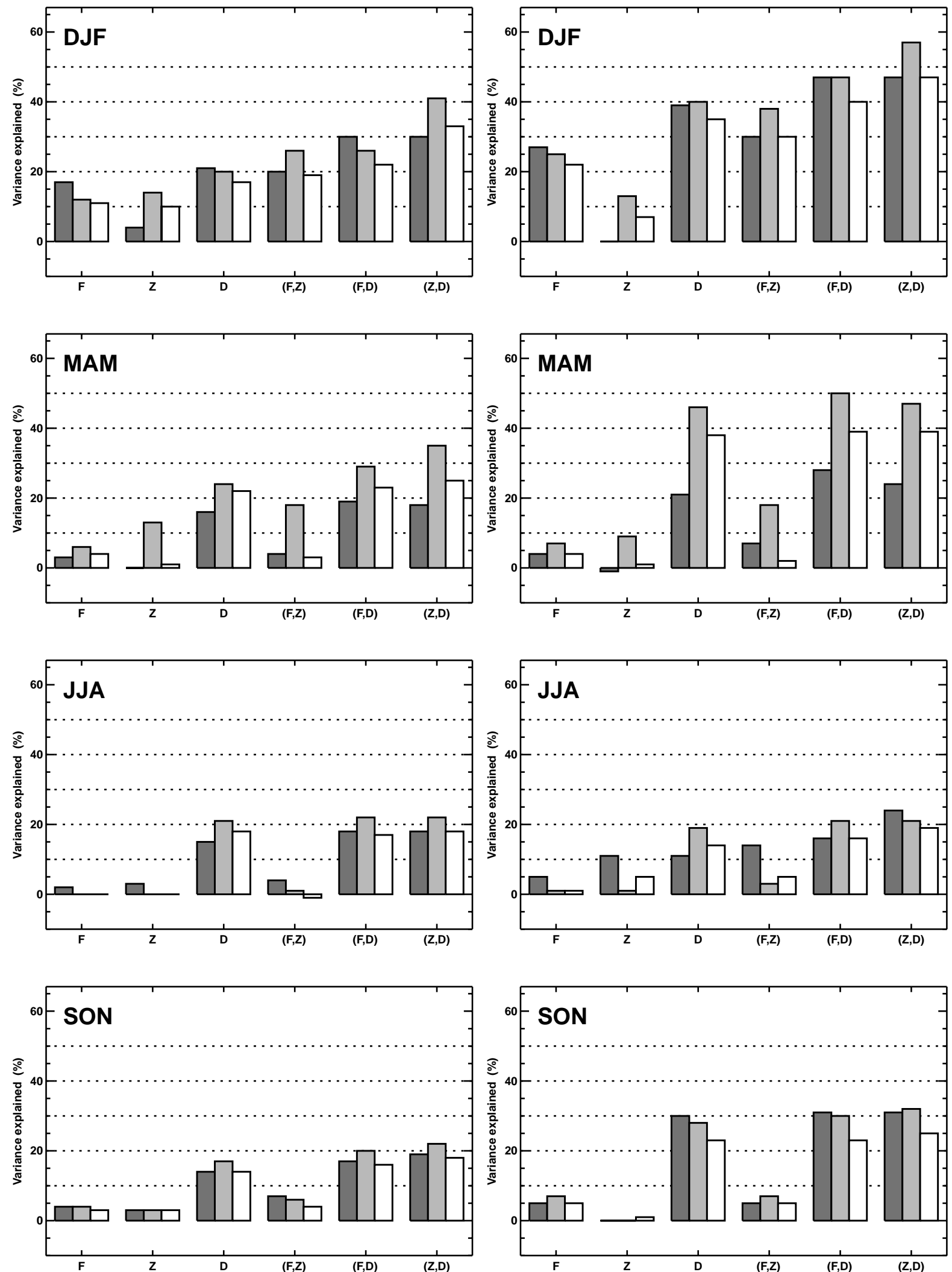

Fig. 9. Central England temperature variance explained by flow strength $(F)$, vorticity $(Z)$, flow direction (D), or 3 combinations of bivariate predictors $[(F, Z),(F, D),(Z, D)]$. Results are on a seasonal basis and for 2 time scales (left-hand column: on a daily basis; right-hand column: evaluated following accumulation of daily values into seasonal means). ( $\square$ ) Observed data; ( $\square$ ) HadCM 2 output; and $(\square)$ amount of HadCM 2 temperature variance that the observed relationships would explain 

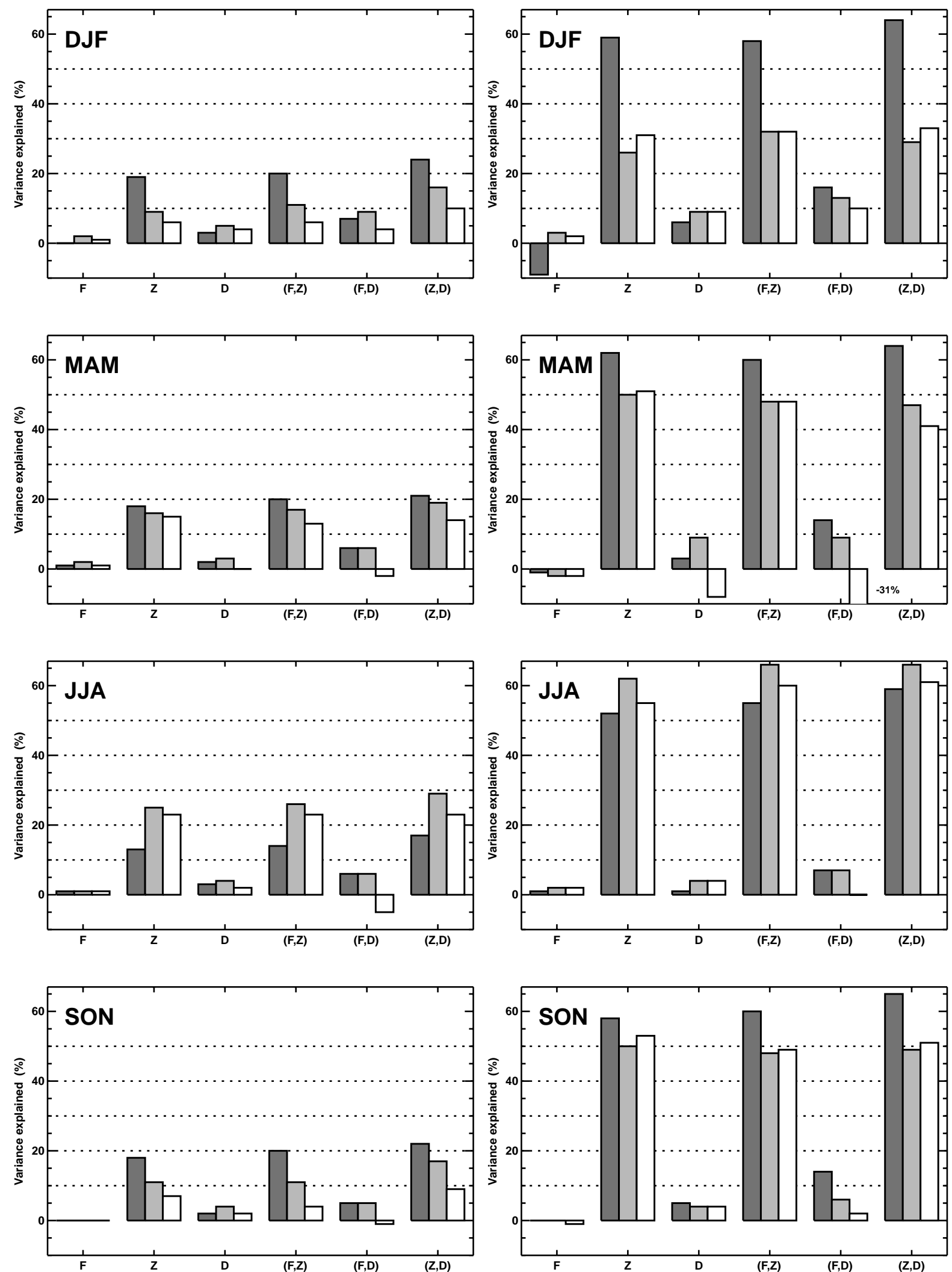

Fig. 10. Central/eastern England precipitation variance explained by flow strength ( $F$ ), vorticity $(Z)$, flow direction (D), or 3 combinations of bivariate predictors $[(F, Z),(F, D),(Z, D)]$. Results are on a seasonal basis and for 2 time scales (left-hand column: on a daily basis; right-hand column: evaluated following accumulation of daily values into seasonal means). ( $\square$ ) Observed data; ( $\square$ ) HadCM 2 output; and ( $\square$ ) amount of HadCM 2 temperature variance that the observed relationships would explain 
ter and the overestimation of the influence of vorticity in the HadCM 2 winter and spring simulations. Flow direction is important in all seasons, as expected.

The importance of vorticity for controlling precipitation shows a seasonality, with least influence observed in summer (Fig. 10). This is not well captured by HadCM 2, which has the strongest vorticity influence in summer and the weakest in winter. Flow strength makes virtually no contribution, while flow direction makes a minor contribution, particularly in the model.

The contribution to climate variability made by synoptic variability is enhanced when longer time scales are considered, due in part at least to a reduced relative contribution of small-scale and site influences. The results shown in the right-hand panels of Figs. $9 \& 10$ are the explained variances after the original and 'synoptic signal' daily temperature and precipitation timeseries are averaged/accumulated into seasonal means. The interannual variation of seasonal mean temperature, excluding summer, is considerably better explained by synoptic variations than is the daily variability, particularly for flow direction. The HadCM 2 simulation also exhibits this increase, although overestimated in spring. The seasonality in the strength of the circulation influence on temperature at both time scales may be due to weaker horizontal temperature contrasts in summer and the increased amount of solar radiation, and hence the enhanced importance of cloud cover variations. Additional analysis is necessary to identify alternative important predictors.

The enhanced explained variance at seasonal scales is clear for precipitation too (Fig. 10), particularly for vorticity. The seasonality in the observed results is weak, with least explained variance in summer. This remains at odds with the seasonality in the simulated results, for which the explained variance of seasonal means is least in winter.

Even if the dark and light grey bars have a similar height in Figs. $9 \& 10$, indicating that synoptic air flow is of similar importance in controlling daily and seasonal temperature and precipitation variability in both datasets, it does not necessarily imply that the relationships between air flow and climate are correct. Visually, we have already described their similarity (with some exceptions), but this can also be quantified. We take the simulated sequence of air flow index values, but use the observed relationships between air flow and temperature (Fig. 4) or precipitation (Fig. 5) to generate the synoptic signal timeseries for that variable. This is then compared with the simulated temperature or precipitation, in terms of the percent variance explained. Results of this exercise are given by the unshaded bars in Figs. $9 \& 10$.

If the observed and simulated relationships between air flow and local climate were identical, then the white and light grey bars would be equal. The light grey bars provide, therefore, the yardstick for comparison. It is impossible for the observed relationships to do better at generating simulated daily anomalies, since the simulated relationships already capture the maximum simulated climate variance at the daily time scale. Nevertheless, for temperature (Fig. 9), the observed relationships do very well at capturing the simulated temperature variations, with the exception of vorticity in spring (which was clearly quite different in HadCM 2 than in the observed record, Fig. 4). For seasonal mean temperature anomalies, the observed relationships also perform almost as well as the simulated ones, except in spring.

The precipitation simulation also provides a very good match, since the observed and simulated relationships between air flow and this variable are almost interchangeable. At the daily time scale (Fig. 10, lefthand panels) the explained variances (light grey and shaded bars) are quite similar for the 3 individual predictors; for seasonal means (right-hand panels) the observed relationships explain as much or even more of the simulated interannual variability of seasonal precipitation totals for some seasons and air flow indices. The main exception is the influence of flow direction on spring precipitation, which is not very important but nevertheless is poorly simulated (see also Fig. 5). Fig. 10 also shows that the incorrectly simulated seasonal cycle in the precipitation variance explained by vorticity is not due to a poor circulation-precipitation link, since use of the observed relationships gives the same result.

\subsection{Bivariate predictors}

Having quantified the influence of individual air flow variables on temperature and precipitation, and how realistic the HadCM 2 simulation is, we can now consider the additional explanative power attained by considering combinations of 2 air flow indices. From a model evaluation point of view, if 2 influences are truly independent and we have validated the model in terms of each influence separately, then there is no need to validate the model in terms of their combined influence. For most seasons and combinations of predictor and predictand variables, the multi-predictor relationships are very similar to what would be expected from a simple combination of univariate (single-predictor) results. It is of interest, however, to assess whether the exceptions to this rule are also captured by the HadCM 2 simulation; 3 such exceptions are described below.

Consider first the frequency distributions: these have been computed by binning the index values, but now each bin is defined by ranges of 2 air flow index values; 
(a)

(b)

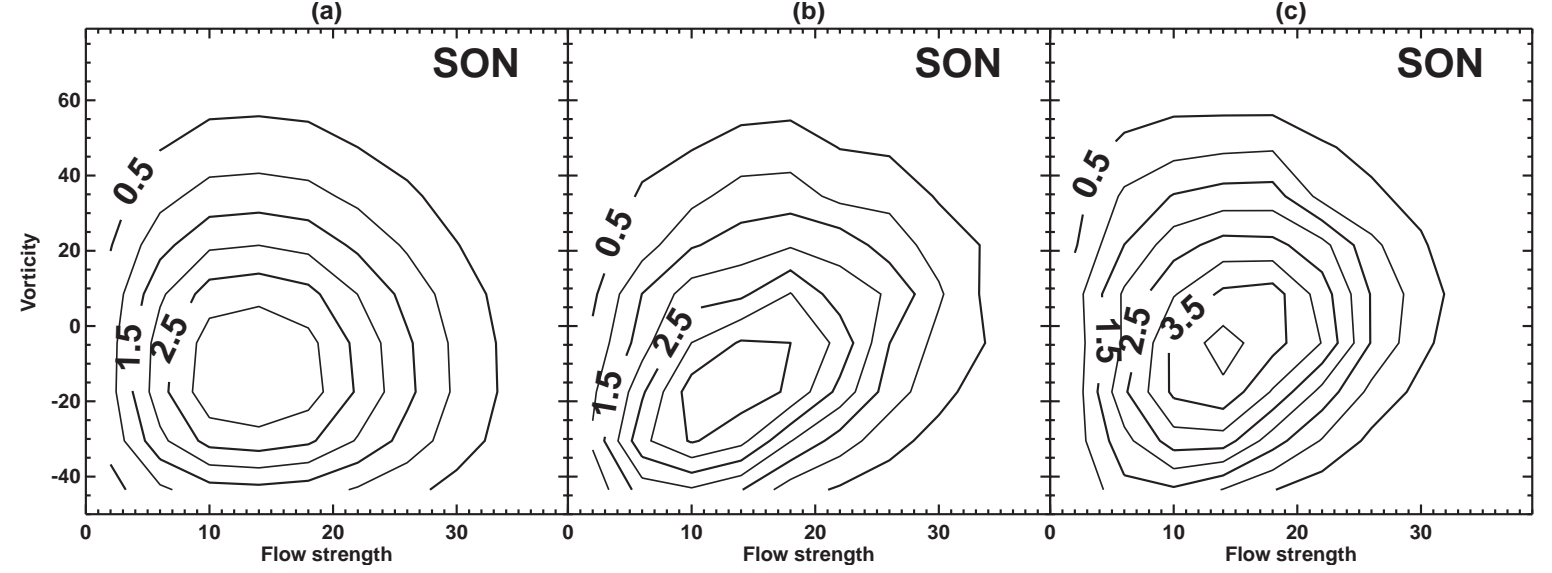

Fig. 11. Frequency distribution (\%) of autumn vorticity and flow strength value pairs. (a) Distribution expected by combining the separate univariate observed distributions; (b) the actual observed bivariate distribution; and (c) the simulated bivariate distribution. Each index is divided into 10 equal-size bins, making 100 bins in total

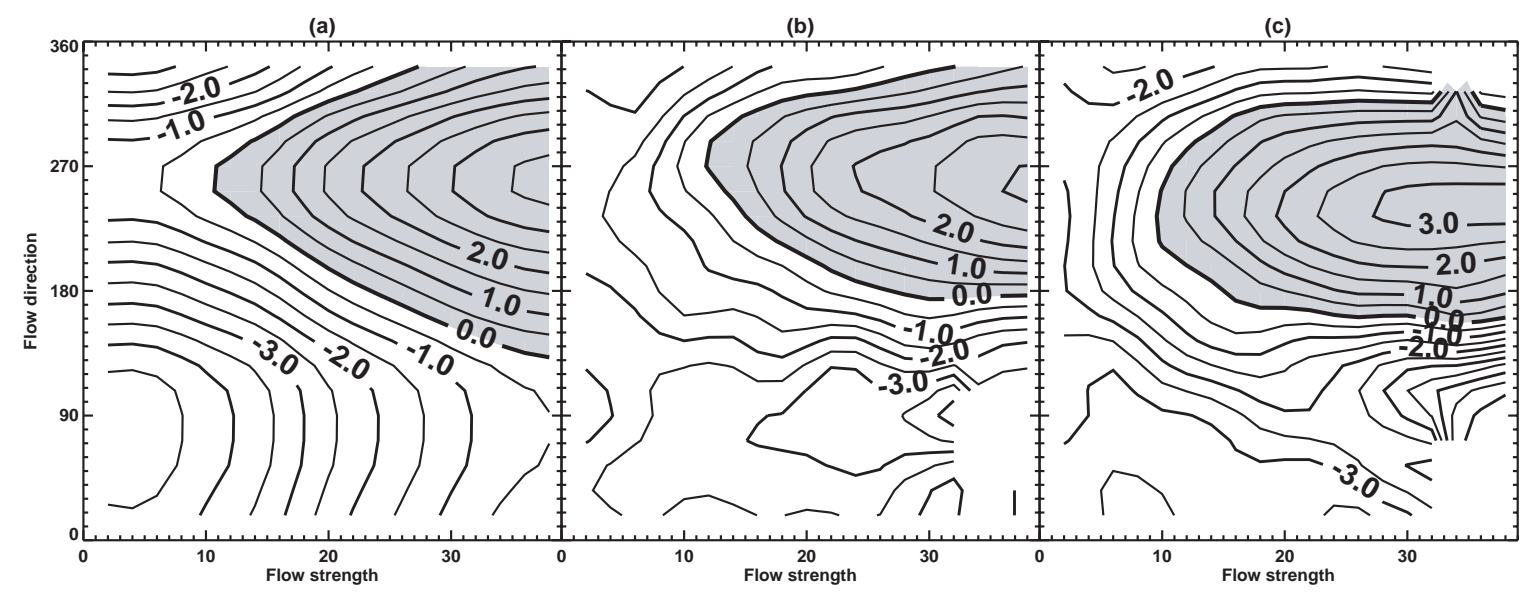

Fig. 12. M ean temperature anomaly $\left({ }^{\circ} \mathrm{C}\right)$ of days that fall in each bin for winter flow direction and flow strength. (a) Distribution expected by combining the separate univariate observed functions; (b) the actual observed bivariate function; and (c) the simulated bivariate function. Each index is divided into 10 equal-size bins, making 100 bins in total

for a day to fall into a particular bin, both indices have to be within the respective ranges. The bivariate distribution of vorticity and flow strength values is stretched in the weak flow/negative vorticity to strong flow/positive vorticity direction (Fig. 11b) compared to what would be expected (Fig. 11a) from the 2 univariate distributions (Fig. 3) under the assumption of independence, and this stretching (i.e. dependence) is apparent in all seasons (only autumn is shown). The HadCM 2 simulation exhibits this non-independence, but to a weaker extent (Fig. 11c). Flow direction and vorticity are independent, but the bivariate frequency distribution for flow direction and strength values shows differences to what would be expected from the 2 univariate distributions. In all seasons, the distribution of flow strength is skewed towards weaker flows on days with easterly flow, and skewed towards stronger flows when the flow is from the west-southwest. The model exhibits similar behaviour.

The influence of synoptic air flow index pairs on temperature also shows some differences to what a linear combination of the univariate relationships would imply. In winter, for example, westerly flow is warm, easterly flow is cold, strong flow is warm and weak flow is cold (Fig. 4). The temperature anomaly structure would then be that shown in Fig. 12a. In fact, the multi-predictor structure (Fig. 12b) indicates that the coldest mean temperatures do not occur when light flow is combined with easterlies, but when strong flow is combined with easterlies. The simulation shows similar results (Fig. 12c).

Neither flow direction nor strength is a strong controller of precipitation, and so the univariate relationships predict that strong easterlies would be only a lit- 


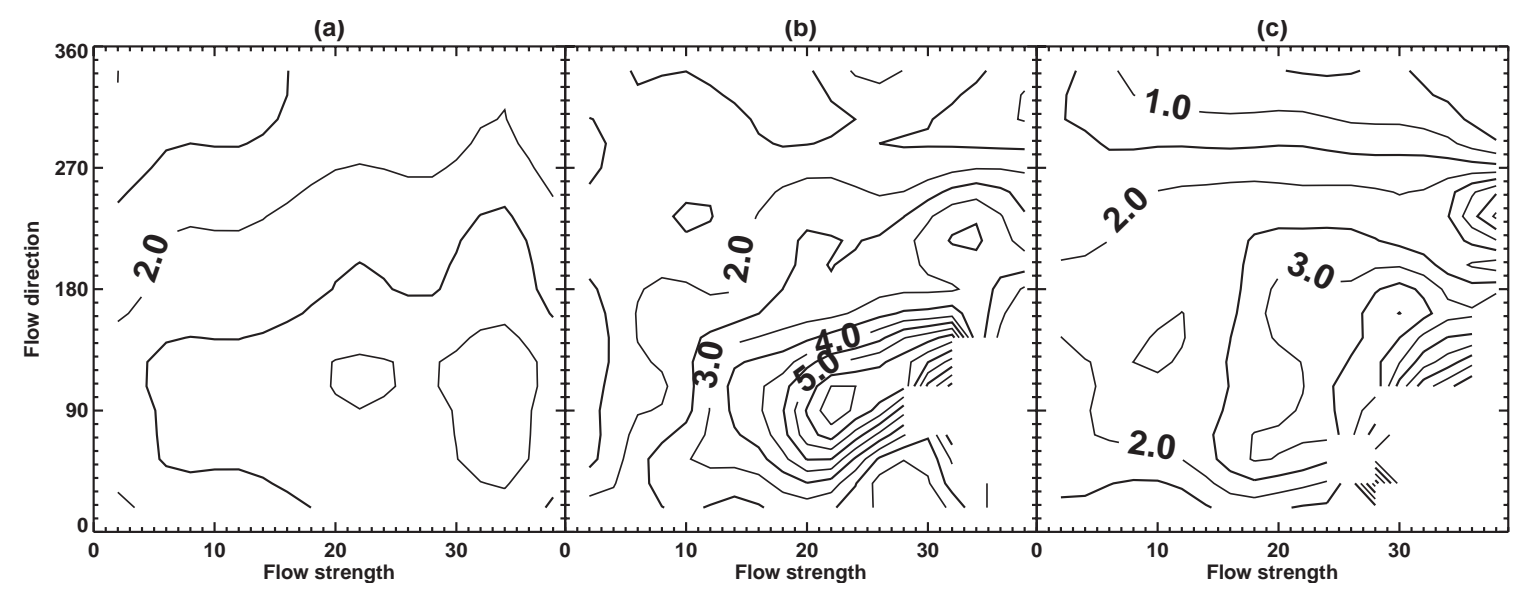

Fig. 13. Mean precipitation $\left(\mathrm{mm} \mathrm{d}^{-1}\right)$ of days that fall in each bin for autumn flow direction and flow strength. (a) Distribution expected by combining the separate univariate observed functions; (b) the actual observed bivariate function; and (c) the simulated bivariate function. Each index is divided into 10 equal-size bins, making 100 bins in total

tle wetter than other synoptic situations (Fig. 13a). In fact, this region of central and eastern England is quite wet under this combination (Fig. 13b), probably evaporating moisture from the North Sea to enhance precipitation. This is true in the observations for all seasons, and the HadCM 2 simulation captures this feature well in winter and summer (despite the simplified land-sea distribution and coarse resolution of the model's North Sea-Fig. 1b), but more weakly in spring and autumn (the latter is shown in Fig. 13c).

The percent explained variances for temperature (Fig. 9) indicate that the multi-predictor relationships do capture more variance than single predictors, except in summer at the daily time scale and autumn at the seasonal time scale. The similarity of the white and light grey bars in Fig. 9 demonstrates the similarity between observed and simulated multi-predictor relationships; these are closest in summer and most different in spring. For precipitation, the vorticity and direction bivariate function $[(Z, D)$ in Fig. 10] explains marginally more variance than other predictors at the daily time scale. At seasonal time scales, variances of the order of 50 to $65 \%$ are obtained provided that vorticity is a predictor. The observed and simulated multipredictor relationships are still fairly interchangeable, in that the simulated precipitation series can be replicated to a similar degree whichever relationships are used, with the exception of the $(F, D)$ combination in spring, summer and autumn.

In Section 4, the influence of biases in the simulated synoptic air flow climate (Fig. 3) on the mean temperature simulated by HadCM 2 were considered for the 3 air flow indices separately (Table 1). The analysis was inconclusive due to the opposing effects of the flow strength and vorticity biases. Using the multi-predictor relationships, the analysis can be extended to consider the influence of biases in the bivariate distributions of each combination of 2 air flow indices. These results are also shown in Table 1. The combined effect of the flow strength and vorticity ( $F, Z$ bias) is weaker, but vorticity is dominant. The small biases introduced by differences in the frequency distributions of flow direction will add small negative biases to this. It would appear, therefore, that the biases in the mean simulated temperature are not due to biases in the simulated synoptic circulation over the UK, although a small contribution may be made in summer.

It would, of course, be of interest to consider the trivariate frequency distribution of air flow index values and the trivariate influence on surface climate, both for analysis of this bias and for model evaluation, but the number of bins would then be so high that the sample in each would be too low to satisfactorily determine the mean values. An alternative, not undertaken here, would be to develop a multiple linear regression model for each season, not using the air flow indices as predictors (since the relationships with climate can be non-linear), but using the temperature or precipitation predicted by each air flow index (via the non-linear curves in Figs. $4 \& 5$ ) as predictors.

\section{SUMMARY AND DISCUSSION}

An existing methodology (Conway et al. 1996) for identifying the influence of synoptic air flow on local climate has been applied to the evaluation of the HadCM 2 global climate model, focusing on the UK region. The synoptic climatology over the UK is well simulated and shows improvements over earlier versions of the UK M eteorological Office climate model. Smaller systematic biases remain, however, with a 
poor simulation of flow direction in spring, a bias towards too many weak/moderate flow days and too few strong flow days, and a skew in the vorticity distribution towards positive vorticity (cyclonic) days compared to observations.

The influence on temperature and precipitation of the geostrophic flow strength, direction and vorticity of the synoptic circulation is generally well simulated. The similarity has been evaluated both visually and quantitatively for mean temperature and precipitation variability, and visually for the probability of wet days and the mean precipitation amount on wet days. For both temperature and precipitation, a maximum of around $20 \%$ of the daily variability can be captured by using the air flow indices; this dramatically increases to $65 \%$ when the interannual variability of seasonal means or totals are considered. Additional explanative power can be obtained by considering the relationship between temperature or precipitation and a pair of air flow indices simultaneously. We have not, however, considered the relationship between temperature and precipitation (as have, for example, Buishand \& Brandsma 1999).

For precipitation, the observed and simulated relationships appear to be almost interchangeable when quantified, despite visual differences. For temperature, using the observed relationships to predict the simulated temperature from the simulated synoptic air flow explains almost as much variability as the simulated relationships, doing least well in spring. The differences are not large however.

These results imply that, for temperature and precipitation over the UK grid boxes considered, the climate variations generated by the $\mathrm{HadCM} 2$ climate model due to synoptic variability are realistic and believable, even at the single grid-box spatial scale (with the caveat that we have not compared how the inter-daily variability within a circulation class may itself vary with the air flow characteristics). This applies to simulations of future climate too, to the extent that if a climate change comes about solely through a change in the synoptic circulation climatology then the results presented here suggest that the temperature and precipitation change will be reliably simulated. Recent studies (e.g. Conway 1998) indicate, however, that the contribution of synoptic circulation changes to anthropogenic climate change may be rather minor, with non-synoptic processes more important. Further work is needed, therefore, to evaluate the reliability with which the HadCM 2 climate model simulates the response of the UK climate to variations in these other processes (larger-scale circulation changes, atmospheric moisture and temperature changes, in situ radiative changes, etc.).

If sub-grid-scale temperature or precipitation is required, thereby necessitating the use of a downscaling procedure, then the results reported here suggest that the simulated grid-box temperature or precipitation should be considered as a potentially useful and reliable predictor, in addition to other factors. A similar conclusion was reached by Widmann \& Bretherton (2000), based on an analysis of reanalysis data over part of the United States.

\begin{abstract}
Acknowledgements. This work has been supported by the UK Department of the Environment, Transport and the Regions (EPG 1/1/48), the Commission of the European Communities (ENV4-CT97-0452) and the US Department of Energy (DEFG02-86ER60397). M odel data from the Hadley Centre were supplied by the Climate Impacts LINK Project (UK DETR EPG $1 / 1 / 68$ ). Precipitation data of Gregory et al. (1991) were made available by agreement of Tom Wigley and Phil J ones of the Climatic Research Unit and J ohn Cole of the Water Research Centre.
\end{abstract}

Appendix 1. Uncertainty ranges

\footnotetext{
Uncertainty ranges have been shown in Figs. 3 to 7 to facilitate comparison of model-derived and observation-derived values. What they represent and how they were computed are described here, but first it is important to understand that they aid in the point-by-point comparison of the 2 curves in each panel. The curves should be compared as a whole visually, and then the uncertainty ranges can be used to identify which points show statistically significant differences.

Although the ranges are displayed either side of the observed curves in Figs. 3 to 7, they are not simply observational uncertainty ranges. They show the range of values in which a model value could fall and still be statistically indistinguishable from the observed value with $90 \%$ confidence, taking into account the observed and simulated variability and sample sizes (reduced appropriately due to autocorrelation in individual samples-Wigley 1983).

The distributions used to estimate the $90 \%$ range (i.e. the 5 and $95 \%$ cutoffs) are a little different in each case. The values in Fig. 4, being sample means of daily temperature anomalies, have a near-normal distribution and, therefore, the Student's $t$ distribution is used to obtain the ranges shown. The values in Figs. $5 \& 6$, being sample means of daily precipitation totals, are not normally distributed. Gregory et al. (1993) showed that the wet day amounts of the UK regional precipitation series can be approximated by the incomplete gamma distribution, and we adopted a M onte Carlo approach to show that the sample means of gamma-distributed random values (using a range of parameters given in Gregory et al. 1993) do follow a near-normal distribution for sample sizes of at least 20 (for large sample sizes this is expected from the Central Limit Theorem). Since only those values computed from a sample of at least $20 \mathrm{~d}$ are shown in Figs. $5 \& 6$, we are justified in using the Student's $t$ distribution again.
} 
Appendix 1 (continued)

Figs. $3 \& 7$ show proportions of successes (i.e. the frequency or probability, p, that an event occurs) and so the base distribution is binomial. However, the normal distribution (with mean $\mathrm{p}$ and standard deviation $\sqrt{\mathrm{pq} / \mathrm{n}}$ is a good approximation to the binomial when $n p>5$ and $n q>5$, where $q=1-p$ and $n$ is the sample size. We therefore base the uncertainty ranges on the distribution of differences between a normal distribution with observed $p, q$, and $n$ and one with simulated $p, q$ and $n$ (the parameters vary from case to case). In Fig. 3 , the only cases where the $\mathrm{np}>5$ criterion is not met are at the high flow strengths in spring and summer ( $p$ is small); here, the range should in fact be somewhat positively skewed compared to that shown, but such a skew does not affect the interpretation of the results. In Fig. 7, only those values based on a sample of at least $25 \mathrm{~d}$ are shown, and of those only the ranges at the extreme negative and positive vorticities in spring, summer and autumn might be in error due to the failure to meet the $\mathrm{np}$ or nq criteria. These minor errors should be considered when interpreting Fig. 7.

Finally, no attempt has been made to include uncertainty ranges in Fig. 8, because the sample sizes involved are smaller and make a point-by-point comparison less meaningful. Consideration should instead be given to the overall shape and level of the curves.

\section{LITERATURE CITED}

Buishand TA, Brandsma T (1999) Dependence of precipitation on temperature at Florence and Livorno (Italy). Clim Res 12:53-63

Busuioc A, von Storch H, Schnur R (1999) Verification of GCM generated regional precipitation and of statistical downscaling estimates. J Clim 12:258-272

Conway D (1998) Recent climate variability and future climate change scenarios for Great Britain. Prog Phys Geogr 22:350-374

Conway D, Wilby RL, J ones PD (1996) Precipitation and air flow indices over the British Isles. Clim Res 7:169-183

Enke W, Spekat A (1997) Downscaling climate model outputs into local and regional weather elements by classification and regression. Clim Res 8:195-207

Gregory J M, Mitchell J FB (1995) Simulation of daily variability of surface temperature and precipitation over Europe in the current and $2 \times \mathrm{CO}_{2}$ climates using the UKMO climate model. Q J R M eteorol Soc 121:1451-1476

Gregory J M, J ones PD, Wigley TML (1991) Precipitation in Britain: an analysis of area-average data updated to 1989. Int J Climatol 11:331-345

Gregory J M, Wigley TML, J ones PD (1993) Application of Markov models to area-average daily precipitation series and interannual variability in seasonal totals. Clim Dyn 8:299-310

Hulme M, Briffa KR, J ones PD, Senior CA (1993) Validation of GCM control simulations using indices of daily airflow types over the British Isles. Clim Dyn 9:95-105

Jenkinson AF, Collison FP (1977) An initial climatology of gales over the North Sea. Synoptic Climatology Branch Memorandum No. 62, M eteorological Office, Bracknell

J ohns TC, Carnell RE, Crossley J F, Gregory J M, M itchell J FB, Senior CA, Tett SFB, Wood RA (1997) The second Hadley Centre coupled ocean-atmosphere GCM : model description, spinup and validation. Clim Dyn 13:103-134

J ones PD (1987) The early twentieth century Arctic highfact or fiction? Clim Dyn 1:63-75

J ones PD, Hulme M, Briffa KR (1993) A comparison of Lamb circulation types with an objective classification scheme. Int J Climatol 13:655-663

Editorial responsibility: Hans von Storch, Geesthacht, Germany
Mearns LO, Schneider SH, Thompson SL, McDaniel LR (1990) Analysis of climate variability in General Circulation M odels: comparison with observations and changes in variability in $2 \times \mathrm{CO}_{2}$ experiments. J Geophys Res 95: 20469-20490

Noguer M (1994) Using statistical techniques to deduce local climate distributions: an application for model validation. Meteorol Appl 1:277-287

Osborn TJ, Hulme M (1997) Development of a relationship between station and grid-box rainday frequencies for climate model evaluation. J Clim 10:1885-1908

Osborn TJ, Hulme M (1998) Evaluation of the European daily precipitation characteristics from the Atmospheric Model Intercomparison Project. Int J Climatol 18: 505-522

Osborn TJ, Briffa KR, Tett SFB, J ones PD, Trigo RM (1999) Evaluation of the North Atlantic Oscillation as simulated by a coupled climate model. Clim Dyn 15:685-702

Palutikof J P, Winkler J A, Goodess CM, Andresen J A (1997) The simulation of daily temperature time series from GCM output, part I: comparison of model data with observations. J Clim 10:2514-2532

Parker DE, Legg TP, Folland CK (1992) A new daily Central England temperature series, 1772-1991. Int J Climatol 12:585-596

Widmann M, Bretherton CS (2000) Validation of mesoscale precipitation in the NCEP reanalysis using a new grid-cell dataset for the northwestern US. J Clim (in press)

Wigley TML (1983) The role of statistics in climate impact analysis. In: Proc 2nd Int Meeting on Statistical Climatology, Lisbon. Natl Inst of Meteorology \& Geophysics, Lisbon. 8.1.1-8.1.10

Wigley TML, J ones PD (1987) England and Wales precipitation: a discussion of recent changes in variability and an update to 1985. J Climatol 7:231-246

Wilby RL, Wigley TML (1999) Precipitation predictors for downscaling: observed and General Circulation Model relationships. Int J Climatol (in press)

Wilby RL, Wigley TML, Conway D, J ones PD, Hewitson BC, Main J , Wilks DS (1998) Statistical downscaling of General Circulation M odel output: a comparison of methods. Water Resour Res 34:2995-3008

Submitted: J une 11, 1998; Accepted: December 18, 1998

Proofs received from author(s): November 25, 1999 